\title{
“DOĞAYLA SÖZLEŞME”Yi KENTLER VE RANT ÜZERINDEN YENIDEN ANMAK
}

\author{
Michel Serres (1994), Yapı Kredi Yayınlar1, \\ Çev. Turhan Ilgaz, 148 sayfa, ISBN: 9789753630917
}

Michel Serres, orijinali "Le Contrat Naturel" (1990) olan "Doğayla Sözleşme" adlı kitabında, doğa ile bir sözleşmenin mümkünlüğü üzerinden tartışma yürütmektedir. Serres'e göre, bir toplumsal sözleşmeden nasıl bahsediyorsak, yeryüzünü dıșarıda bırakmayan bir sözleșme türü olarak “doğayla sözleşme”den de bahsedebilmeliyiz. Kitap doğaya ve insanın doğayla olan ilişkilerine, bu ilişkide sınırın nerede başlayıp nerede bitmesi gerektiğine dair o yıllar için hatta bugün için bile alışık olmadığımız bir açıdan bakmaktadır. Çok sayıda alt başlıktan oluşan kitapta temel konular; savaş ve barış, bilim ve hukuk, doğayla sözleşme ile bağlar ve çözülmeler ana başlıkları altında toplanmıştır.

Kitabın; tarih, edebiyat ve görsel sanatlara dair göndermeler, mitler ve metaforlar ile zenginleştirilmiş şiirsel bir anlatım dili vardır. Bu yönüyle kitap, çevreyle ilgili felsefi bir çalışmadan daha ötedir. Kitapta ekoloji sözcüğünün hiç kullanılmıyor olması da kitabın içindeki farklı kaygılar ve arayışların bir yansımasıdır. Serres, 2000 yılında yazdığı Le Retour au Contrat Naturel'de, Doğayla Sözleşme kitabında ekoloji teriminin neden geçmediğini açıklar: "Doğayla Sözleşme, ne bir bilimsel ekoloji kitabl, ne de ekolojinin ideolojisinden bahseden bir kitaptır; aksine, küresel nesneler ve küresel özneler yaratan bu çă̆ın kapitalist toplumunu anlamanın bir yoludur." Felsefe ve matematik alanlarında birikimi olan ve çalışmalarının (Parasite, Genesis, the Five Senses, the Birth of Physics, Times of Crisis, Biogea vb.) çoğunda doğa felsefesine odaklanan yazar, kendisini ekolojist olarak da, derin ekolojist olarak da kabul etmemektedir.

Kitap; gerekçelendirmeden ziyade bir tartışma, üzerinde düşündürme, farklı pencerelerden farklı bakış açıları sunma gibi bir yönelimle yazılmıştır. $\mathrm{Bu}$ anlamda Serres'in, açık ve net olmak gibi bir derdinin de olmadığını söylemek mümkündür; yazar, ortaya attı̆ğ fikrin savunusunu yaparken konuyu, 
birlikte düşünegelmediğimiz örneklerle ve çeşitli düzlemlerde farklı kavramlarla örerek, bir anlamda fikir egzersizi yaptırmaktadır. Serres'in kitapta anlatısını yaparken izlediği yol, kısa hikayeler kullanmak ve bunların "doğayla sözleşme"ye duyulan ihtiyaç ile örtük bir bağını kurmaktır.

Klasik bilim anlayışında insanı her şeyin merkezine koyan, atomik, tek yönlü bir nedensellik bir anlayışı hakimken; bugünkü bilim anlayışına, karşı1ıklı ilişkiler ve ağlar üzerinden giden bir bakış açısı hakimdir. $\mathrm{Bu}$ noktada, Serres'in söylemini, doğa ile olan ilişkiler ve bağlar üzerinden kurması, bilimin bugün geldiği noktayı içselleştirme çabası anlamında oldukça değerlidir. Bu gezegen, insanlara yaşam ortamı sunmakta olduğuna göre, onunla olan ilişkilerimizi düzenlemek ve bir denge kurmaya çalışmak, bu yaşam ortamının sürekliliğini garanti altına alabilmek için gereklidir. İnsanlar dahil tüm canlılar, bu gezegenin bir parçasıdır ve sistem, herhangi bir bileşeni dışlamadan birlikte çalışmak durumundadır. "Aslında, Yeryüzü bizimle güç, barış ve karşıllklı etkileşimin terimleriyle konuşuyor ve bu da bir sözleşme yapmaya yeter" (s. 54).

Serres'in kitabında belirttiği şekliyle; "Sözleşme terimi, köken olarak sıkan ve çeken hat anlamına gelir: Bağlardan oluşan bir düzenek, dili kullanmaksızın, bağlanmış olan her öğenin, her bir kişiden ve sistemin kendisinden haberdar olduğu bu esnek zorunluluklar ve özgürlükler sisteminin devamını, aynı şekilde herkesin güvenliğini de sağlamaktadır." (s. 121). Grupların toplum sözleşmesine; dünya tehlikeli olmaya başladığı zaman zorunlu hale gelmiş olan ilişkileri tanımlayan bir doğa sözleşmesi eklenmelidir (s. 123).

Sözleşme, ille de bir dili varsaymaz: Bir bağlar düzeni yeter (s. 125). Yazılmış haliyle sözleşme, içerdiği hükümlerin altına adlarını yazan kişileri mecbur birakır ve bağlar (s. 126). 1992'deki Rio Summit ve 1997'de imzalanan Kyoto Protokolü gibi anlaşmalar, yeryüzünü uluslararası politik arenada yasal bir taraf yapmıştır. Yeryüzü kaynaklarının sınırsız olmaması, bizi planlı davranmaya zorlamaktadır. Bu anlamda anlaşmalar gibi kent planları da, sınırlı kaynakların yönetilmesinin bir aracı olarak görev yapmaktadırlar. Planlamanın bugün durduğu nokta kısmen bu idealden uzak görünse de; planlama, özünde rasyonel bir hareket tarzı olarak kaynakların hesaplı kullanılmasının garantisidir. Toprağın hesapsız kullanılması, başarısız bir planlamaya ve dolayısıyla içerisinde yaşamaktan memnuniyet duymadığımız kentlerin oluşumuna yol açmaktadır.

Doğayla Sözleşme'de; felsefe, doğabilim, kentleşme, etik, çevre etiği ve haklar alanlarının kesişiminde bir tartışma yürütülmektedir. Haklar konusunda dikkati çeken konu, hakların insan hakları ile sınırlı olmamasıdır. Serres, insan dışındaki varlıkları barındıran doğanın da hakları olduğuna dair çarpıcı bir 
söylem geliştirmektedir. Bugüne dek üzerine çokça yazılıp çizilen kitabı, doğanın bize söylediklerine en az kulak kabarttığımız yerler olan "kentler" üzerinden yeniden değerlendirmek, günümüzde doğanın kentteki konumunu anlama ve anlamlandırma çabasında olan meslek alanları için gerekli görülmektedir. Serres (s. 94)'e göre; halihazırda, kentte oturan, eskiden kentsoylu diye anılan kişi, dünyayı hiç tanımaz. Bundan böyle yönetici; insan bilimlerinin, sitenin sokaklarının ve duvarların dışına çıkmak, toplum sözleşmesinden yukarıya doğru yükselip doğa sözcüğüne, dünyaya geldiğimiz koşulların kökensel anlamını geri vererek, yeni bir doğa sözleşmesi icat etmek zorundadır (s. 94). "Kocaman bir doğa parçası kentin göbeğine düşüyor; fizik bilimlerine ait güzel bir nesne birdenbire toplum bilimlerinin alanina düşüyor!'” (s. 87).

Serres, toplum bilimleri ve doğa bilimleri ikiliği gibi; kenti ve doğay1 birbirinin karşıtı iki kavram olarak, birbirini dışlayan iki olgu olarak görür. Kentler ve doğa birlikte yaşama yollarını bulmalıdır. "Bin tane kültür, bir tane doğa" vardır (s. 89). "Yeryüzü, bizim düşleyemediğimiz zamanlarda, atalarımız yokken de vardl, bizler bugün olmasak da var olabilirdi ve olabilecektir." (s. 47). Doğanın var olabilmek için bize ihtiyacı yoktur fakat, biz var olabilmek için doğaya muhtacız. Serres, doğayla bir sözleşme yapmamanın bizi kayıplara sürükleyeceğini; buna karşın yapacağımız bir sözleşmenin ise bizi hiçbir kayba uğratmayacağını söyler: "Eğer eylemlerimizin masum davranışlar olduğuna karar verir de doğa-toplum arasındaki bahsi kazanırsak hiçbir şey kazanmış olmayız, tarih de tıpk eskisi gibi sürer: Ama eğer bahsi kaybedersek bir takım olasi afetlere karşı hazırlanamadan, her şeyi kaybederiz. Bir de bunun tersine, sorumluluklarımızı kabullenmeyi seçelim: Eğer bahsi kaybedersek, hiçbir şey kaybetmeyiz; ama ĕger kazanırsak, tarihin oyuncuları olarak kalır ve her şeyi kazanırız. Bir yanda hiç ya da kayıp, öte yanda kazanç ya da hiç: Her türlü kuşkuyu ortadan kaldirmiyor mu bu?" (s. 17).

Dünya ile, doğal olanla, doğayla uzlaşmak zorundayız: "Uzlaşmak", karşısındakinden fedakarlık talep eden bir kararı çağrıştırdığından, yanlış bir ifadedir. Çünkü dünya biz olmasak da var olabilir oysa biz onsuz var olamayız. Toplumsal sözleşmeler, insanın hakimiyet ve sahiplenmesinin edilgin nesneleridirler ve dünyayı dışarıda bırakırlar. Bu da dünyanın tahrip olmasına sebep olur. Toplum sözleşmesi ve politika ortaklı̆̆ i insanlarla, özneyle sınırlanır ve nesneyi, dünyayı sskalar. Bu yüzden toplumsal sözleşmeye doğa sözleşmesini eklememiz gerekir. Dünya, doğa sözleşmesinin içine girdiği anda barış da devreye girer (s. 8-9).

Serres insanlar arasındaki savaşa, insanların birbirlerini daha kötü bir duruma doğru sürükledikleri bir olgu olarak bakar. Savaşı, gruplar ya da uluslar arasındaki hukuk ilişkilerinden biri olarak tanımlamak gerekir: Bu elbette bir eylemsel durum, ama özellikle bir hukuk durumudur. Savaş, şiddetin kaba 
patlamasıyla değil, örgütlenişi ve hukuksal statüsüyle belirginlik kazanır; böylece de, bir sözleşmeyle. Tarih, şiddetli çarpışmaların yargısal hükümlerle sona erdirilişi ve durağanlaştırılmasına götüren savaşla başlar. Tarih içinde; önce şiddet, ardından savaş, arada hukuk sözleşmesi olagelir. İlkel toplum sözleşmesini yeniden gözden geçirmek, hatta yadsımak gereklidir. Dünya ile yapılması gereken yeni bir ittifak vardır: doğayla sözleşme (s. 25-27).

Goya'nın bir tablosunda iki düellocu bir bataklıkta kavga etmektedirler. İki kavgacının dışında, üçüncül konumda olan şey, mücadelenin içine gömüldügü bataklıktır. Sahne, insan-doğa ilişkisini örneklemektedir (s. 13). Mitolojide Akhileus da; savaşarak düşmanlarına, aslında dünyaya ve bilmeden kendisine zarar verir (s. 14). Goya'nın resmindeki düellocular kendilerine karşı savaşırken, aslında beraber batağa gömüldüklerini görmezler. $\mathrm{Bu}$, tarihin doğaya kör baktığının bir yansımasıdır (s. 19). "Şimdiye kadar dünyayı yönetme söylemimiz düşmanlıktan geçiyordu, ayn şekilde tarihin zamanının motoru da kavgaydl. Ufukta topyekün bir değişiklik var: bizim değişmemiz" (s. 22). Eğer savaş ve şiddet, bilinçli olarak ve ilan edilmiş biçimleriyle önümüzde duruyorsa, nesnel şiddet daha önceki hiçbir sözleşmede bulunmayan yollara götürmektedir (s. 23). "Dünyayı esirgemek için aramızdaki barışa ve kendimizi esirgemek için de dünya ile barışa karar vermek zorundayız" (s. 10 ve 37).

Yeryüzü üzerinde geçirdiğimiz süre; su, hava, toprak gibi doğanın temel unsurlarına erişebildiğimiz takdirde devam edebilir. "Belki talih, belki de bilgelikten, Fransız dili, 'zaman' ve 'hava'yı anlatmak için tek bir sözcük kullanır (temps)" (s. 41). Bu, havayı tüketirken dünya üzerinde kalan zamanımızı da tükettiğimizin bir göstergesi gibidir. Serres (s. 27); çirkinlikleri ve kazara yaydıkları pislikleriyle kimyasal tesisler, rekabetçi büyük ölçekli hayvan yetiştirme işletmeleri, atom santralleri, dev petrol tankerleri, bombalar, silahlar vs.'nin, ortak ve sözleşmeli olarak insanlar üzerinde egemenlik arayışından başka amaçları olmaksızın, şiddeti geri getirdiklerini ifade eder. İnsanoğlunun düşüncede ya da iletişimde birinci, örgütlenmiş varlıkların en haberli olanı ve maddi bütünlüklerin en etkini olmakla beraber; iklimin açttğı savaşta yenilip kaybolup gidebilecek kadar güçsüz olduğuna dikkati çeker (s. 32). "Maddesel ve duyumsal çöplüğün dăğlmasıyla, dünyanın güzelliğini kapatıyor ya da siliyor ve onun çeşitliliklerinin bereketli yayılışını salt kendi yasalarımızın çorak ve güneşli tekliğine indirgiyoruz. .... Eğer akılcı yanımız gerçeği, gerçek de akılcı yanımızı kavrasaydı, akıllıca yapılmış işletmelerimiz geride atık birakmayacaklardl..." (s. 36).

"Olanca yakıcıllğıyla, tarih doğaya kör bakıyor" (s. 19). Serres, kendimizle ve birbirimizle uğraşmaktan yeryüzünü anmaz olduğumuzu, yeryüzünü unutmanın aslında zamanı ve mekanı unutmak anlamına geldiğini söyler. Oysa mekan yitimi, mekana kazınmış bilgilerin de yitimi anlamına gelmektedir. Mekan yitimi ile birlikte, kendi elimizle kendi hafızamızı 
zayıflatmakta ve hatta kaybetmekteyiz. Çünkü mekan, içerisindekilerle birlikte bir anlam kazanmaktadır, içinde hiçbir şey olmayan bir mekan aslında mekan değildir, boşluktur. Mekan içindeki nesneler de, onlar yaşama katıldıklarında bir anlam kazanmakta; herhangi bir olay da o nesnelerle kurduğumuz bağlar üzerinden açıklanmaktadır. İnsan olarak ontolojimizi kurma şeklimiz; sosyal olandan, dolayısıyla zamandan bağımsız olamadığı gibi, mekandan da bağımsız olamamaktadır. Elbette, mekan yalnızca insan eliyle oluşturulan yapay unsurlardan ibaret değildir, doğa olmaksızın ne insandan ne de insan eliyle yapılmış nesnelerin mekanlarından bahsedilebilmektedir.

Yaşadığımız mekanlar, günümüzde ve giderek artan biçimde kentler tarafından domine edilmektedir. Yaşadığımız gezegen küresel olarak kentleşmektedir: Ekümonopolis. Metropoller ve onları çevreleyen uydu kentlerin oluşturduğu sistem, yerküreyi bir ağ gibi kuşatmaktadır. Serres (s. 84), kitabında "Devasa metropollerde geçen hayatımızda, yitirilmiş cennetleri düşlercesine, sürekli ve eksiksiz, ögretinin herkesi her bir kişinin kölesi kıldiğg o korkunç Atinaları düşler olduk" demektedir. Oysa kendi varlığımızı borçlu olduğumuz doğayı yeniden hatırlamak, modern yaşam mekanları olarak organize ettiğimiz kentlerde doğaya daha fazla yer açmakla mümkündür.

Bir olguyu anlamak için onu tanımanız gerekir; bu doğa için de söz konusudur. Yaşamımızı sürdürdügümüz kentler, doğadan uzak düşmüştür, uzakta olan ise bize yabancıdır. Kentin içinde doğaya daha çok alan açabilme becerisini kazandığımızda, doğayı anlayabilir ve bir arada yaşamasını öğrenebiliriz. $\mathrm{Bu}$, doğanın bir parçası olduğumuzu hatırlamamızı; ağaçlar, toprak, hava ve su var olduğu için hala yaşamımızı sürdürebildiğimizi fark etmemizi sağlayacaktır. İnsan, doğadan ve doğanın kurallarından ayrı düşünülebilecek ve yaşayabilecek bir mutlak gerçeklik konusu değildir. $\mathrm{Bu}$ anlamda, bugün insanların yalnızca toplum için geliştirdikleri kuralların yekûnu olan hukuk, insanın yeryüzündeki yaşamının devamlılığı için yeterli değildir.

Serres (s. 51)'in ifadesiyle hukuk, insanlar arasındaki istismarcı asalaklığı sınırlamaya çalışan bir görev üstlenmekle birlikte, nesnelerin üzerindeki istismarcı asalaklığı içermemektedir. Serres; nesnelerin kendileri de hukuk öznesi haline gelirlerse, o zaman bütün terazilerin bir dengeye doğru yönelebileceğini ifade eder. İnsanın kendi varlığını garanti altına almaya çalışırken izlediği yol tek boyutludur ve toplumsal bir varlık oluşuna ilişkindir. $\mathrm{Bu}$, Rousseau'nun “toplumsal sözleşme"sine bizi götürmüş olmakla birlikte hukuk, yalnızca sosyalin değil, bütünün haklarını gözeten daha kapsayıcı bir yol açmalıdır.

Misır ve Roma, uzun sürmüş ve muazzam imparatorlukların gerçekleştiricileri olarak birer hukuk varlı̆̆ıdır. XII Levha Roma'yı, Maat da 
Mısır'1 ayakta tutmuştur. Kimyanın ve mekaniğin iki kurucu kahramanı, Galilei ve Lavoisier, tarihin yargılayıcılığında saygınlıklarını kazandıkları kilisenin mahkemeleri karşısına çıkarıldıklarında, zamanın adaletini utanca belemişlerdir. Hukuk, hangi bilim adına yargılayıp hüküm vermiştir? Bilim, hukuk hakkında ne hakla karar vermiştir? Bilimler, işte böylesi eylemlerde bulmuşlardır başlangıçlarını, tarihe adalet saraylarının ve davaların kapılarından girmişlerdir. Yunan medeniyetinin tüm tarihi, yargılayan akılla kanıtlayan aklın, bu düşman ve ikiz kardeşlerin o ortak ve trajik biçimde hareketli yaşamını anlatmaktadır. Bizim bugünkü meselemiz, bunların ne zaman ve nasıl ortak yaşamlı hale gelecekleri olmalıdır (s. 76-78).

Galilei, hukuka karşı, yeryüzünün kendi çevresinde dönüşünün savaşını vermiştir. Galilei’nin, devinen ve devinimi zamanın hukukçuları gözünde hiçbir şey ifade etmeyecek olan Yeryüzüne yönelik çağrısı, yerkürenin fethine yönelik, kesin bilme için çıkarılmış bir mülkiyet sözleşmesi gibidir (s. 100). Bilim ve hukuk, tarihsel karşılaşmalarında; eskiden felsefenin yaptığı gibi, tarihsel açıdan gücünü ve etkinliğini oluşturan bütün ayrıntıları, birleştirmeye uğraştı̆̆ için, hem korumakta, hem de kaybetmektedir. Leibniz'e göre, "her şeyin yalnızca kendi yeterli nedeni değil, aynı zamanda teslim edilmesi gereken hakkı vardır" (s. 104). Bilgiden ve ardı sıra da bilimden önce gelen aklın gerekliliği, olaya ya da kanıtlamaya uygunluktan kaynaklanmaktadır. Akıl, yargının üzerinde yükselmekte olduğundan yarg1 gücümüz de aklın ürettiklerinden faydalanmak durumundadır (s. 107-108).

Serres'e göre; uzun vadeli ve had safhadaki bir soruna bulunacak çözüm, etkili olabilmek için en azından sorunun önemine denk düşmelidir. Binlerce yıllık gelenekler, şimdi ölmüş olan kültürlerce biriktirilmiş deneyimler, uzun vadenin belleğidir. Var ediş, uzun vadeye gereksinmiştir. Bizler ise yok edişe ayarlanmış olan kısa vadeli yanıtlar ve çözümler öneriyoruz. Uzun vadeli bir girişimde, kısa vadeli araçlarla başarıya ulaşılamaz. Hakimiyet ancak kısa vadeli olmakta ve köleliğe dönüşmekte; aynı şekilde, mülkiyet de hızlı bir iz bırakma olarak kalmakta ya da tahribatla sona ermektedir (s. 48).

Mısır'da Nil'in taşkınları, mülkiyet kurumunun ortaya çıkışına ve yerleşmesine aracılık etmiştir: Taşkınlar alüvyonlu vadideki ekilebilir tarlaların sınırlarına kadar toprağı sular altında bıraktığında, krallık ölçümcüleri suyun çekilme hızına göre, payları yeniden dağıtmak üzere yeni baştan ölçüyorlardı. Tufan dünyayı yeniden düzensizliğe, sıfır zamana, doğaya döndürüyor; ekilebilir tarlaların sınırlarını ve kenarlarını siliyor ve bir anda mülkiyetler ortadan kayboluyordu. Kaotik hale gelmiş toprağa dönen ölçümcüler, onu yeni baştan dağıtıyorlar ve böylece, silinmiş olan hukuku, yeniden ihya ediyorlardı (s. 67-68). Doğa, belki de bizim mülkiyetle ilgili bilgilerimizi silmek istemişti... 
19. yüzyılda toprak üzerindeki özel mülkiyet hakları, sınırlı bir hak biçimine dönüştürülmüştür. Nedeni, mülkiyet hakkının kamu yararına aykırı biçimde kullanılmasına engel olmaktır. Kamu yararı her ne kadar kişi değil topluma ve toplumun kurumlarına referans veriyorsa da sistemin çalışması için haklar ve sınırlılıkların iyi tanımlanmış olması gerekmektedir. Haklar ve sınırlılıkların nesnel çerçevesi, bizim insan-doğa ilişkisinde de ortak yaşam sisteminin sürebilmesi için gözetmemiz gereken bir anlayıştır. Toprağı satın aldığımızda toprağa sahip olduğumuzu zannetmek bir yanılsamadır. Çünkü toprağı sınır tanımaz bir "rant" konusu yaptığımız ölçüde; topraktan ve doğadan uzaklaştığımızı, hatta beton yığınları arasında toprağı görmekte bile güçlük çektiğimizi fark ederiz. Toprağa sahip olmayı, toprak yüzeyine alabildiğince yayılmak ve gökyüzüne olabildiğince yükselmekten ibaret sanmak kendimize yabancılı̆̆ımızın bir yansımasıdır.

Serres, bizim doğadan gelmiş olmamıza rağmen, doğa varlığını bize borçluymuş gibi hareket ederek sonunda onun ölümüne seyirci kalabileceğimizi vurgulamakta ve bu durumu anlatmak üzere şu örneği vermektedir: Annesi öldügünde büyük kızı Marie, annesini kucağına aldığında, sanki anne olan kendisidir (s. 134). En karmaşık şeylerin bile ardında hep ölüm vardır, herşey ölümün hep aynı şekilde eşlik ettiği bir dizi peş peşe kalkışın sonucu olmuştur (s. 137). "Hepimiz, baştan aşağı topraksızlaştırılmış astronotlar haline geldik: eskiden bir yabancının yabancıya karşı yabancı olabildiği gibi değil, ama birlikte, bütün insanlar kendi toprağına yabancı hale geldik." (s. 139). Toprağa dayanamazsak, nasıl devinebiliriz ki? Ayaklarımız karaya sağlamca basmalıdır, o olmaksızın ondan öte nereye doğru kalkışa geçeceğimizi bilemeyiz. Gerçekten de can çekişen yaşı annemizin anası haline gelmek zorunda değil miyiz? Doğumun ne yöne doğru gittiğine karar veremeyeceğimiz ölçüde karşılıklı olan bu ortak yaşam bağlantıları, doğa ile sözleşmeyi çizmektedir (s. 140-141).

Üzerinde yaşadığımız toprağa yabancı hale gelmemek için özel mülkiyet-kamu yararı mekanizmasında kurulmaya çalışılan denge, kapitalist sistemin beslendiği rantın ilgi alanına girmemektedir. Yeryüzü kaynaklarının sınırsız olmadığı gerçeğinden hareketle rant, doğayla yapacağımız bir sözleşmede yerini alabilecek bir maddedir. Serres'in kitabın çeşitli kısımlarında üzerinde durduğu gibi hukuk, bilimsel gerçeklerden beslenmelidir. Kentin ranta yenik düşmesi, doğanın insana yenik düşmesine benzetilebilir. Bununla birlikte aralarında temel bir ayrım vardır; doğa, doğası gereği mağlup olamaz: Doğa insan olmasa da varlığını sürdürebilir; varlığını sürdürebilmek için doğaya muhtaç olan taraf insandır. İnsan öldüğünde doğayı arkasında götüremez ama doğa öldüğünde insanı arkasında götürecektir, bu durumda yaşam ihtimali yoktur. İnsanoğlunun sonunu imgelemek için Serres, kitabını bitirirken (s. 142); kendini kalakalmış hissettiğini söyler ve ekler: “..... deprem sırasında 
sevinci tattım. .... Bin türlü gereksiz bă̆, yok edilmiş olarak çözülürken, dengesini bulamayan ayakların altında, yerin derinliklerinden doğru, öz varlık, fondaki gürültü, homurdanan dünya yükseliyor: .... Alışık olduğum evrenime, titrek uzayıma, stradan çıplaklıklara, özüme, tastamam esrikliğe dönüyorum".

Yrd. Doç. Dr. Gül Şimşek Atatürk Üniversitesi Şehir ve Bölge Planlama Bölümü,

Arş. Gör. Selcan Bayram Gazi Üniversitesi Şehir ve Bölge Planlama Bölümü 